\title{
PENGARUH VARIASI DAYA DAN WAKTU EKSTRAKSI BERBANTU GELOMBANG MIKRO TERHADAP TOTAL FENOL DAN pH BUNGA ROSELA (Hibiscus sabdariffa $L$.)
}

\author{
The Effect Of Power Variation And Time Of Micro Wave Extraction On Total \\ Phenol And pH Of Rosela Flower (Hibiscus Sabdariffa L.)
}

\author{
Ike Sitoresmi M Purbowati ${ }^{1}$, Sujiman ${ }^{1}$, Ali Maksum ${ }^{1}$ \\ ${ }^{1}$ Jurusan Teknologi Pertanian, Fakultas Pertanian, Universitas Jenderal Soedirman, \\ Jalan Dr. Suparno , Karangwangkal, Purwokerto 53123, Indonesia \\ Ikesitoresmi@yahoo.co.id
}

\begin{abstract}
Functional drinks are drinks containing bioactive compounds such as phenol, vitamin $C$, and anthocyanins. One of the plants containing bioactive compounds is roselle. These compounds are contained in flower petals, and are susceptible to heat. Based on this, it is necessary to know the effect of microwave power and the length of time the extraction of the roselle petals is appropriate, so that the yield of high bioactive compounds is obtained. This study aims to determine the effect of variations in microwave power and extraction time, on total phenol and pH of roselle petal extract. This study used a randomized block design (RBD). Two factors studied were the microwave power method $(P)$, which consisted of 100 watts $(P 1), 175$ watts $(P 2), 250$ watts (P3), 325 watts (P4), and 400 watts (P5), while the Extraction Time (T) consists of 1 minute (T6), 3 minutes (T7), 5 minutes (T8), 7 minutes (T9), and 9 minutes (T10). The results show the best microwave power at 325 watts (P4) with total phenol $75.755 \mathrm{mg} / 100$ gram and $\mathrm{pH} 2.4$, while the best extraction time at 5 minutes (T8) with total phenol was $75.843 \mathrm{mg} / 100$ gram, and pH was 2.49 .
\end{abstract} Keywords: antibacterial; extraction; phenol; microwave power

\begin{abstract}
ABSTRAK
Minuman fungsional adalah minuman yang mengandung senyawa bioaktif seperti fenol, vitamin C, dan antosianin. Salah satu tanaman yang mengandung senyawa bioaktif adalah rosela. Senyawa tersebut terdapat didalam kelopak bunga, dan bersifat rentan oleh panas. Berdasarkan hal tersebut, maka perlu diketahui pengaruh daya microwave dan lama waktu ekstraksi kelopak bunga rosela yang tepat, agar diperoleh rendemen senyawa bioaktif yang tinggi. Penelitian ini bertujuan untuk mengetahui pengaruh variasi daya microwave dan lama waktu ekstraksi, terhadap total fenol dan $\mathrm{pH}$ ekstrak kelopak bunga rosela. Penelitian ini menggunakan rancangan acak kelompok (RAK). Dua faktor yang diteliti yaitu metode daya microwave (P), yang terdiri dari 100 watt (P1), 175 watt (P2), 250 watt (P3), 325 watt (P4), dan 400 watt (P5), sedangkan Lama Waktu Ekstraksi (T) terdiri dari 1 menit (T6), 3 menit (T7), 5 menit (T8), 7 menit (T9), dan 9 menit (T10).Hasil penelitian menunjukkan daya microwave terbaik yaitu pada daya 325 watt $(\mathrm{P} 4)$ dengan total fenol 75,755 mg/100 gram dan $\mathrm{pH}$ 2,4, sedangkan lama waktu ekstraksi terbaik pada 5 menit (T8) dengan total fenol sebesar 75,843 $\mathrm{mg} / 100$ gram, dan $\mathrm{pH}$ sebesar 2,49.
\end{abstract}

Kata kunci : antibakteri; ekstraksi; fenol; daya microwave

\section{PENDAHULUAN}

Salah satu Bahan Tambahan Pangan (BTP) adalah bahan pengawet, menurut Hernani dan Raharjo (2005), bahan pengawet umumnya digunakan untuk mengawetkan pangan yang bersifat mudah rusak. Bahan ini dapat menghambat atau memperlambat proses fermentasi, pengasaman atau peruraian yang disebabkan oleh mikroba. Namun penggunaan bahan pengawet dan antioksidan sintetis pada saat ini tidak 
direkomendasikan karena diduga dapat menyebabkan penyakit kanker (Carcinogenic Agent) dan berakibat pada keracunan makanan. Hasil dari penyidikan oleh Badan Pengawasan Obat dan Makanan (BPOM) ditahun 2016 menangani 251 perkara pelanggaran di bidang obat dan makanan. Pemeriksaan pada triwulan III tahun 2017 terhadap 6.271 sarana distribusi makanan menunjukkan hasil sebanyak 2.107 $(33,60 \%)$ tidak memenuhi ketentuan (TMK) salah satunya dikarenakan produk pangan mengandung bahan berbahaya seperti bahan pengawet sintetis yang melebihi batas pemakaian. Mengingat dampak bahaya penggunaan pengawet sintetis tersebut, maka perlu usaha untuk menemukan bahan pengawet dari bahan yang alami (Noviantari et al., 2012).

Rosela (Hibiscus sabdariffa) merupakan salah satu tanaman obat yang akhir-akhir ini penggunaannya semakin meningkat terkait khasiat yang dimiliki (Badrelin, 2014). Kelopak bunga rosela dapat mencegah berbagai penyakit seperti hipertensi, diabetes, dan diuretik (Patel, 2014). Setiap bagian tanaman rosela mempunyai kandungan senyawa kimia yang bermanfaat untuk pengobatan maupun bahan makanan (Wahid, 2008). Salah satu diantaranya adalah corolla (mahkota) bunga rosella yang memiliki kandungan kimia antara lain antosianin, betakaroten, vitamin C, thiamin, riboflavin, flavonoid dan niasin (Maryani, 2008). Bunga rosela juga memiliki beberapa kandungan zat seperti gossypetin, glukosida, hibiscin, flavonoid, theflavin, katekin dan antosianin (Widyanto dan Nelistya, 2008). Ekstrak bunga rosela mengandung alkaloid, flavanoid, saponin dan tanin yang mampu menghambat aktivitas bakteri Escherichia coli dan Staphylococcus aureus pada media agar (Rostinawati, 2009).

Agar lebih fleksibel dalam pemanfaatannya, bahan bioaktif dalam kelopak bunga rosela perlu diekstraksi dari sel tanaman tersebut. Pemilihan dan cara ekstraksi yang tepat bergantung pada senyawa aktif yang dikandung simplisia. Salah satunya yaitu Microwafe Assisted Extraction (MAE). Menurut Kurniasari et al. (2008) MAE merupakan teknik untuk mengekstraksi bahan-bahan tanaman yang terlarut dengan bantuan energi gelombang mikro. Daya gelombang mikro dan waktu merupakan dua faktor yang saling mempengaruhi kandungan dari hasil ekstraksi. Kombinasi daya yang rendah dan waktu ekstraksi yang panjang dan sebaliknya merupakan pilihan yang bijak mengingat kombinasi tersebut dapat menghindari terjadinya degradasi termal 
produk. Ekstraksi berbantu gelombang mikro merupakan alternatif terbaik untuk menggantikan proses ekstraksi konvensional karena lebih efisien, yaitu waktu ekstraksi lebih singkat, penggunaan pelarut lebih sedikit, selektivitas tinggi terhadap molekul target, dan kualitas produk lebih baik (Li et al., 2009; Wang et al., 2010).

\section{Selama proses ekstraksi} menggunakan metode MAE, ada beberapa faktor yang dapat mempengaruhi hasilnya. Faktor-faktor yang mempengaruhi proses ekstraksi antara lain ukuran bahan, suhu ekstraksi, jenis pelarut, waktu ekstraksi, rasio pelarut dan bahan baku (Watson, 2005). Besar daya dan lama waktu ekstraksi tertentu dapat mempengaruhi kandungan senyawa bioaktif dalam ekstrak rosela terutama senyawa yang berfungsi sebagai antibakteri. Maksum (2017) telah mengeksplorasi optimasi ekstraksi rosela dengan hasil kondisi optimum daya ekstraksi sebesar 250 watt dan waktu ekstraksi selama 4,91 menit, namun penelitian tersebut menggunakan rosela dengan pengeringan yang belum optimal. Karenaitu Purbowati et al. (2018) menemukan bahwa daya dan waktu MAE yang optimal untuk ekstrak rosela yaitu dengan pengeringan 7 jam menggunakan cabinet dryer. Permasalahannya, bagaimana pengaruh variasi daya microwave dan lama waktu ekstraksi terhadap karakteristik kimia ekstrak kelopak bunga rosela. Penelitian ini bertujuan untuk mengetahui pengaruh variasi daya microwave danlama waktu ekstraksi terhadap total fenol dan $\mathrm{pH}$ ekstrak kelopak bunga rosela.

\section{METODE}

Penelitian ini dilaksanakan di Laboratorium Teknologi Pertanian, Fakultas Pertanian, Universitas Jenderal Soedirman, Purwokerto. Penelitian ini berlangsung mulai Januari 2018 hingga Juni 2018.

Bahan-bahan yang digunakan yaitu bunga rosela merah kering (Hibiscus sabdariffa) yang didapat dari pasar Kediri (Jawa Tengah), Bumi Herbal Dago (Bandung), aquades, folin 10\%, $\mathrm{Na} 2 \mathrm{CO} 37,5 \%$ acidic etanol, Staphylococcus aureus, Escherichia coli, Pseudomonas Aeruginosa dan Bacillus Cereus yang didapat dari Fakultas Biologi Universitas Jenderal Soedirman.

Alat-alat yang digunakan dalam penelitian ini adalah blender (philips), erlemeyer (herma dan iwaki), gelas ukur (pyrex), microwave (electron), timbangan digital (AND), spektrofotometer UV-VIS (Shimadzu), tabung reaksi (pyrex), plastik pp, kertas saring, corong, alumunium foil, 
gelas plastik kecil, botol cokelat, filler, labu ukur $10 \mathrm{ml}$, pipet ukur, spatula, $\mathrm{pH}$ meter, buffer, Autovortex, mikro pipet, tip, kapas, autoclave, lamine airflow, cawan petri, oven listrik. Seperangkat alat untuk analisis kimia.

Penelitian eksperimental ini menggunakan Rancangan Acak Kelompok yang disusun secara faktorial. Faktor yang dicoba terdiri dari 2 faktor yaitu, variasi daya microwave $(\mathrm{P})$ terdiri atas 100 watt (P1), 175 watt(P2), 250 watt (P3), 325 watt (P4), dan 400 watt (P5); lama ekstraksi terdiri atas 1 menit (T6), 3 menit (T7), 5 menit (T8), 7 menit (T9), dan 9 menit (T10). Diperoleh 25 kombinasi perlakuan, dan setiap kombinasi perlakuan diulang sebanyak 2 kali, maka diperoleh 50 unit percobaan.

\section{AnalisisTotal Senyawa Fenolik}

Total fenol ditentukan menggunakan metode Folin-Ciocalteu. Sebanyak $0,4 \quad \mathrm{~mL}$ larutan sampel ditambahkan 1,5 mL Folin-Ciocalteu reagent $(10 \%, \mathrm{v} / \mathrm{v})$. Setelah diinkubasi 5 menit dicampur dengan $1,5 \mathrm{~mL}(\mathrm{w} / \mathrm{v})$ larutan $\mathrm{Na}_{2} \mathrm{CO}_{3} 7,5 \%$. Setelah 90 menit inkubasi pada suhu ruang dan gelap diukur absorbansi pada $765 \mathrm{~nm}$. Asam galat digunakan sebagai standar. Hasil yang didapat direpresentasikan sebagai $\mathrm{mg}$ ekuivalen asam galat (GAE)/g bahan (Chew et al., 2009).

Data yang diperoleh dianalisis menggunakan uji $\mathrm{F}$ (analisis ragam) pada taraf kepercayaan 95\%. Apabila hasil menunjukkan pengaruh yang nyata, maka dilanjutkan dengan uji Duncan Multiple Range Test (DMRT) pada taraf 5\%.

\section{HASIL DAN PEMBAHASAN}

1. Total fenol

a. Pengaruh lama ekstraksi kelopak bunga rosela terhadap total fenol yang dihasilkan

Nilai rata-rata total fenol disajikan pada Gambar 1. 


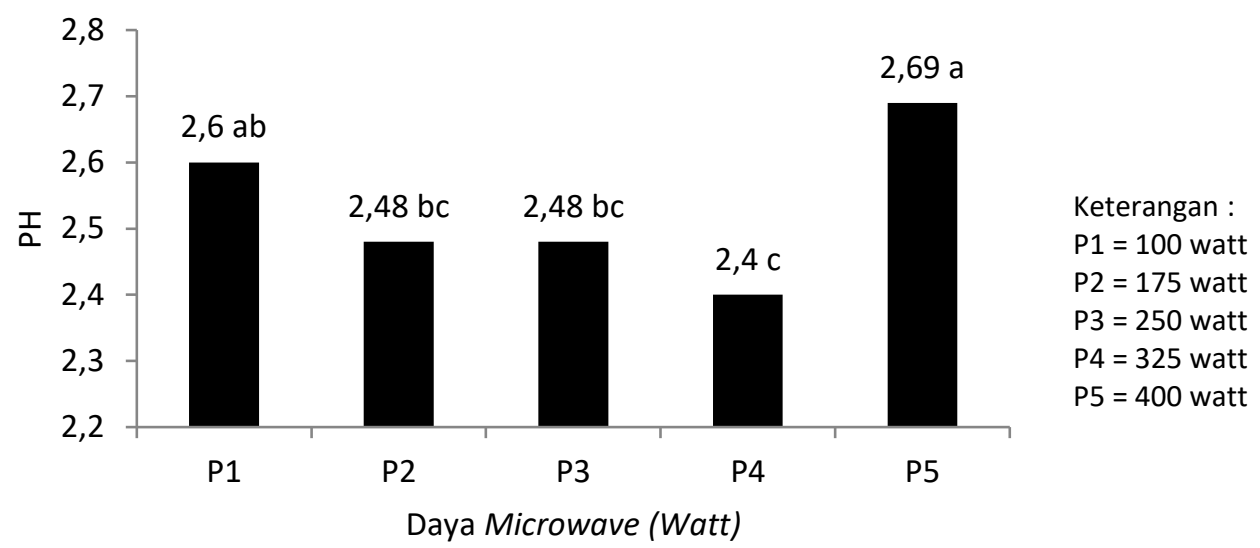

Gambar 1. Nilai rata-rata total fenol ekstrak kelopak bunga rosela pada variasi daya microwave.

Daya gelombang mikro merupakan parameter penting lain dalam prosedur ekstraksi berbantu gelombang mikro. Variasi daya yang digunakan adalah 100, 175, 250, 325 dan $400 \mathrm{~W}$. Hasil penelitian menyatakan bahwa nilai rata-rata total fenol dari daya terendah mengalami kenaikan hingga pada daya 325 watt, hal ini terjadi karena kandungan total fenol sudah mulai terekstrak keluar dengan adanya penambahan daya pada ekstraksi. Ekstraksi didasarkan pada perpindahan massa komponen zat padat ke dalam pelarut. Dalam hal ini perpindahan mulai terjadi pada lapisan antar muka, kemudian berdifusi masuk ke dalam pelarut. Proses pengekstraksian komponen kimia dalam sel tanaman yaitu pelarut organik menembus dinding sel dan masuk ke dalam rongga sel yang mengandung zat aktif. Untuk selanjutnya zat aktif larut dalam pelarut organik di luar sel, sehingga larutan terpekat berdifusi keluar sel. Proses demikian terjadi berulang-ulang hingga terjadi keseimbangan antara konsentrasi cairan zat aktif di dalam dan di luar sel (Shirazian dan Ashrafizadeh, 2010).

Pemanasan menggunakan gelombang mikro merupakan dampak interaksi antara kandungan bahan dengan gelombang elektromagnetik. Prinsip pemanasan menggunakan gelombang mikro berdasarkan tumbukan langsung dengan material atau pelarut yang diatur oleh dua fenomena, yaitu konduksi ionik dan rotasi dipole. Konduksi ionik mengacu pada migrasi elektroforetik ion dalam pengaruh perubahan medan listrik. Dalam pengaruh suatu medan listrik, ionion yang terdapat pada bahan yang dipanaskan akan bergerak dan bergesekan 
sehingga menimbulkan panas(Pan et al., 2001).

Gelombang mikro bekerja dengan melewatkan radiasi gelombang mikro pada molekul-molekul yang terdapat pada bahan, sehingga molekulmolekul ini akan menyerap energi elektromagnetik tersebut (Jain et al. 2009). Kondisi demikian menyebabkan kandungan total fenol mengalami kenaikan. Namun demikian, fenol sangat sensitif terhadap panas. Apabila suhu meningkat terus, maka akan menurunkan kandungan total fenol yang dihasilkan, ditunjukkan pada daya 325 - 400 watt, total fenol mengalami penurunan. Sesuai dengan pernyataan Liyana dan Shahidi (2005), bahwa kandungan senyawa fenolik menurun seiring dengan meningkatnya suhu. Total fenol pada daya microwave 400 watt sebesar $66,76 \mathrm{mg} / 100$ g, dan nilai rata-rata total fenol paling tinggi pada daya microwave 325 watt $(\mathrm{P} 4)$ sebesar 75,755 mg/100 g.

Dapat disimpulkan bahwa daya microwave kelopak bunga rosela yang optimal terjadipada daya microwave 325 watt, kemudian menurun pada daya microwave yang lebih tinggi (400 watt). Menurut Gao et al. (2006) pada daya gelombang mikro yang lebih besar (400 1200 Watt), variasi daya yang diberikan tidak berpengaruh pada hasil ekstraksi. Pernyataan tersebut sesuai dengan penelitian Maksum (2017), bahwa daya yang terlalu tinggi dapat menyebabkan panas yang tinggi pula, sehingga senyawa fenol cenderung lebih cepat terdegradasi.

b. Pengaruh lama waktu ekstraksi kelopak bunga rosela terhadap total fenol yang dihasilkan

Nilai rata-rata fenol pada lama waktu ekstraksi disajikan pada Gambar 2.

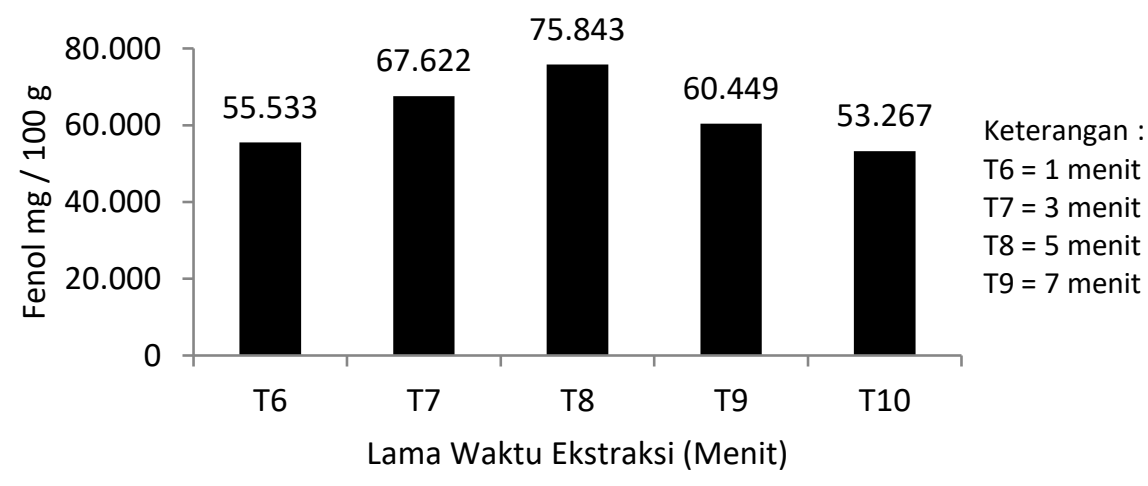

Gambar 2. Nilai rata-rata total fenol ekstrak kelopak bunga rosela pada berbagai lama ekstraksi. 
Hasil penelitian menyatakan bahwa nilai rata-rata total fenol pada lama ekstraksi 1 menit mengalami kenaikan hingga pada lama ekstraksi 6 menit. Kemungkinan kandungan total fenol sudah mulai terekstrak keluar dengan adanya penambahan waktu pada ekstraksi (Purbowati et al., 2016). Pemanasan dengan menggunakan gelombang mikro merupakan akibat dari adanya interaksi antara kandungan bahan dengan gelombang elektromagnetik. Seperti diketahui bahwa konduksi ionik pada pemanasan microwave mengacu pada migrasi elektroforetik ion dalam pengaruh perubahan medan listrik. Ion-ion yang terdapat pada bahan yang dipanaskan akan bergerak dan bergesekan sehingga menimbulkan panas. Gelombang mikro bekerja dengan melewatkan radiasi gelombang mikro pada molekul-molekul yang terdapat pada bahan, sehingga molekul-molekul ini akan menyerap energi elektromagnetik tersebut (Jain et al. 2009). Karena itu lama ekstraksi dapat mempengaruhi total fenol yang dihasilkan. Makin panjang lama waktu ekstraksi menyebabkan suhu makin tinggi, demikian pula kelarutan senyawa fenolik dalam pelarut juga makin besar.

Difusi yang terjadi juga makin besar, sehingga proses ekstraksi akan berjalan lebih cepat. Namun demikian fenol sangat sensitif terhadap panas, oleh karena itu penambahan waktu yang terus menerus dapat menurunkan kandungan total fenol yang dihasilkan. Hal ini tercermin pada lama ekstraksi 7 menit, kandungan total fenol sudah mengalami penurunan, demikian yang terjadi dengan lama waktu ekstraksi 9 menit, kandungan total fenol yang didapatkan paling rendah $(53,267 \mathrm{mg} / 100 \mathrm{~g})$. Nilai rata-rata total fenol paling tinggi terjadipada lama ekstraksi 5 menit yaitu sebesar 75,842 $\mathrm{mg} / 100 \mathrm{~g}$.

Dapat disimpulkan bahwa semakin panjang lama ekstraksi kelopak bunga rosela, maka nilai rata-rata total fenol semakin menurun. Lama ekstraksi gelombang mikro yang panjang akan mengakibatkan turunnya rendemen, dan mengakibatkan terjadinya dekomposisi senyawa fitokimia, seperti halnya pendapat Chen et al. (2008) dan Pan et al. (2001).

\section{2. $\mathbf{p H}$}

Nilai $\mathrm{pH}$ adalah derajat keasaman yang digunakan untuk menyatakan tingkat keasaman atau kebasaan yang dimiliki oleh suatu larutan.

a. Pengaruh daya microwave kelopak bunga rosela terhadap nilai $\mathrm{pH}$ yang dihasilkan

Nilai rata-rata $\mathrm{pH}$ yang disajikan pada Gambar 3. 


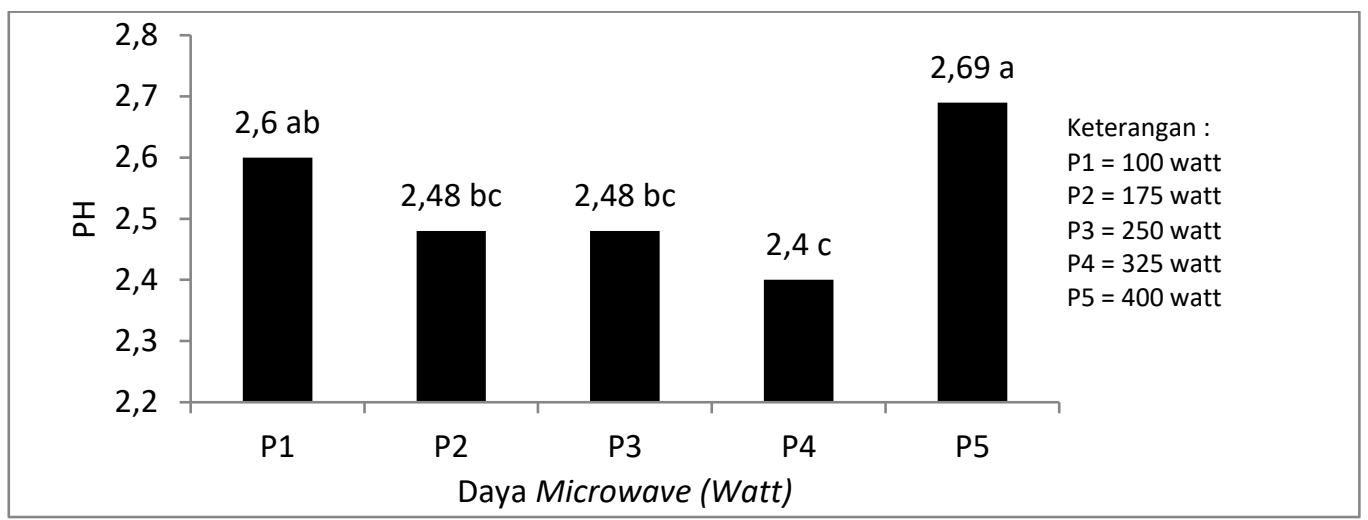

Gambar 3. Nilai rata-rata $\mathrm{pH}$ ekstrak kelopak bunga rosela pada variasi daya microwave.

Perbedaan daya microwave dapat mempengaruhi nilai rata-rata $\mathrm{pH}$ yang dihasilkan. Berdasarkan hasil penelitian ini, $\mathrm{pH}$ yang paling rendah adalah 2,4 terjadi pada daya microwave 325 watt. Hal ini sejalan dengan nilai rata-rata kandungan total fenol yang paling tinggi pada daya tersebut. Senyawa fenol mampu mereduksi senyawa radikal bebas dengan mendonorkan atom hidrogennya kepada oksigen singlet, dan kemudian fenol akan teroksidasi menjadi radikal fenoksi yang stabil.

Radikal fenoksi merupakan senyawa yang relatif stabil karena akan terjadi resonansi pada cincin fenolik, sehingga radikal tersebut tidak membentuk radikal bebas baru, melainkan radikal fenolik yang dapat bereaksi dengan radikal bebas lain guna menghentikan reaksi berantai (Xu, 2012).
Semakin rendah pH ekstrak, berarti dalam ekstrak tersebut semakin banyak $\mathrm{H}^{+}$ bebas. $\mathrm{H}^{+}$ini dapat meregenerasi senyawa antioksidan dengan cara berikatan dengan radikal fenoksi membentuk senyawa antioksidan kembali. Hasil tersebut menunjukkan bahwa pada $\mathrm{pH}$ yang semakin meningkat, senyawa fenolik yang terkandung di dalam ekstrak juga mengalami kerusakan. Kemungkinan, terkait dengan struktur anthosianin yang merupakan golongan flavonoid atau turunan dari fenol mudah berubah akibat perubahan $\mathrm{pH}$ dan juga kekuatan ionik larutan.

Hubungan nilai $\mathrm{pH}$ dan antosianin menurut Laleh et al.(2006), bahwa tingginya paparan cahaya, $\mathrm{pH}$, dan suhu, dapat merusak molekul antosianin. $\mathrm{pH}$ makin tinggi maka makin banyak 
degradasi yang terjadi pada molekul antosianin.
Nilai rata-rata $\mathrm{pH}$ yang disajikan pada Gambar 4.

b. Pengaruh lama ekstraksi kelopak bunga rosela terhadap nilai $\mathrm{pH}$ yang dihasilkan

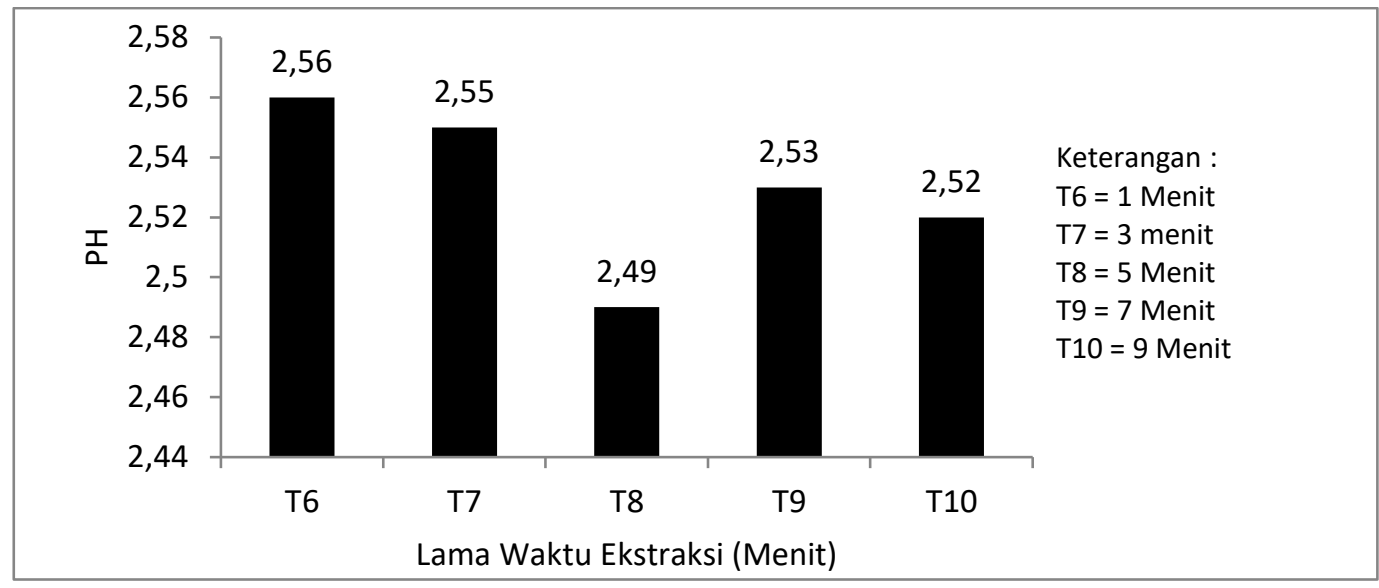

Gambar 4. Nilai rata-rata $\mathrm{pH}$ ekstrak kelopak bunga rosela pada berbagai lama ekstraksi.

Perbedaan lama ekstraksi mempengaruhi nilai rata-rata $\mathrm{pH}$ yang dihasilkan. Pada penelitian ini, lama waktu ekstraksi mempengaruhi nilai ratarata $\mathrm{pH}$, kemungkinan terkait dengan jumlah total fenol yang terdapat dalam ekstrak. Gambar 4 menunjukkan pada lama waktu ekstraksi 6 menit didapatkan $\mathrm{pH}$ yang paling rendah yaitu 2,49, sedangkan pada lama waktu ekstraksi yang sama diperoleh kandungan senyawa fenol yang paling tinggi yaitu sebesar $75,843 \mathrm{mg} / 100 \mathrm{~g}$.

Hasil penelitian menunjukkan bahwa semakin tinggi nilai rata-rata total fenol yang dihasilkan, maka semakin rendah nilai rata-rata $\mathrm{pH}$ ekstrak kelopak bunga rosela yang didapatkan. Hal ini dikarenakan fenol memiliki sifat yang cenderung asam, sehingga senyawa tersebut cenderung mudah melepaskan ion $\mathrm{H}^{+}$dari gugus hidroksilnya $(-\mathrm{OH})$. Senyawa fenol mampu mereduksi senyawa radikal bebas dengan mendonorkan atom hidrogennya kepada oksigen singlet dan kemudian fenol akan teroksidasi menjadi radikal fenoksi yang stabil.

Radikal fenoksi merupakan senyawa yang relatif stabil karena dapat terjadi resonansi pada cincin fenolik, sehingga radikal tersebut tidak 
membentuk radikal bebas baru, melainkan radikal fenolik dapat bereaksi dengan radikal bebas lain untuk menghentikan reaksi berantai $(\mathrm{Xu}, 2012)$. Oleh karena itu, senyawa fenolik dapat dikategorikan sebagai antioksidan primer. Semakin rendah $\mathrm{pH}$ ekstrak, semakin banyak $\mathrm{H}^{+}$ bebas. $\mathrm{H}^{+}$ini dapat meregenerasi senyawa antioksidan dengan cara berikatan dengan radikal fenoksi membentuk senyawa antioksidan kembali.

Antosianin merupakan golongan dari flavonoid atau turunan dari fenol. Hubungan nilai pH dan antosianin menurut Laleh et al. (2006) tingginya paparan cahaya, $\mathrm{pH}$, dan suhu dapat merusak molekul antosianin. $\mathrm{pH}$ tinggi dapat memperbesar degradasi yang terjadi pada molekulantosianin. Selim et al. (2005) menambahkan bahwa pada pH 2-4 antosianin rosela masih memiliki retensi yang cukup tinggi, namun pada $\mathrm{pH}$ 6-8 warna ekstrak cenderung kebiruan. Kandungan senyawa fenol pada rosela yang mempengaruhi $\mathrm{pH}$ dan warna adalah antosianin. Hal ini karena kandungan fenolik dalam rosela, sebagian besar ditentukan oleh sifat antosianin didalamnya.

\section{KESIMPULAN}

Daya microwave berpengaruh pada total fenol dan $\mathrm{pH}$ ekstrak kelopak bunga rosela. Daya microwave terbaik yang didapatkan pada ekstrak dengan daya microwave 325 watt, dengan total fenol sebesar 75,755 mg/100 $\mathrm{g}$ dan $\mathrm{pH}$ sebesar 2,4. Lama Ekstraksi juga berpengaruh terhadap total fenol dan $\mathrm{pH}$ ekstrak kelopak bunga rosela. Lama waktu ekstraksi terbaik yaitu 6 menit dengan total fenol sebesar 75,843 mg/100 g, dan pH sebesar 2,49.

\section{DAFTAR PUSTAKA}

Badrelin, H. Nabel, A.,N.W. and Blundan, G. 2014. Phytochemical, Pharmacologycal and Toxicological aspect of Hibiscus sabdariffa. Academic Press. New York

Chen, Y.H., Wang, J.P. and Jiang, H.Q. 2008. Optimization of extraction technology of total flavonoids from mulberry leaves by orthogonal design. Food and Drug., 3: 17-18.

Chew, Y. L., Goh, J. K., and Lim, Y. Y. 2009. Assessment of in vitro antioxidant capacity and polyphenolic composition of selected medicinal herbs from leguminosae family in Peninsular Malaysia. Food Chemistry. 116:13-18.

Gao, M., Song, B., and Lin, C. 2006. Dynamic microwave assisted extraction of flavonoids from Saussurea medusa maxim culture cells. Journal Biochemical Engineering. 332:79-83.

Hernani dan Raharjo, M. 2005. Tanaman Berkhasiat Antioksidan. Penerbit Swadaya. Jakarta.

Jain, T., Jain, V., Pandey, R., Vyas, A., \& Shukla, S. S. 2009. Microwave Assisted Extraction for Phytoconstituents - An Overview. Asian Journal Research Chemistry , 1 (2): 19-25.

Kurniasari, L., Hartati, I., dan Ratnani, R. D. 2008. Kajian ekstraksi minyak jahe menggunkan microwave assisted extraction (MAE). Jurnal Kimia. 4(2): 25-28. 
Laleh, G.H., H. Frydoonfar, R. Heidary, R. Jameei, dan S. Zare. 2006. The Effect of Light, Temperature, $\mathrm{pH}$ and Species on Stability of Anthocyanin Pigmens in Four Berberis Species. Pakistan Journal of Nutrition. 5 (1):90-92.

Li, C., Du, H., Wang, L., Shu, Q., Zheng, Y., Xu, Y., Zhang, J., Yang, R. and Ge, Y. 2009. Flavonoid composition and antioxidant activity of tree peony (Paeonia section moutan) yellow flowers. Journal of Agricultural and Food Chemistry. 57:8496-8503.

Liyana-Pathirana, C., Shahidi, F. 2005. Optimization ofextraction of phenolic compounds from wheat using response surface methodology. Food Chem., 93:47-56.

Maksum, A. dan Purbowati, I. S. M. 2017. Optimasi ekstraksi senyawa fenolik dari kelopak bunga rosela (Hibiscus sabdariffa Linn) berbasis gelombang mikro. Agrin. 21 (2) 91-102.

Maryani, H. dan Kristiana, L. 2008. Khasiat dan Manfaat Rosela. Agromedia Pustaka. Jakarta.

Noviantari., Ilza, M., Sari, N. I. 2012. Pengaruh Penambahan Ekstrak Rosela (Hibiscus sabdariffa L.) Terhadap Mutu Fillet Ikan Jambal Siam (Pangasius hyhopthalmus) Segar Selama Penyimpanan Suhu Kamar. Fakultas Perikanan dan Ilmu Kelautan. Universitas Riau.

Pan, X., Niu, G. and Liu, H. 2001. Microwave assisted extraction of Tranchiones from Salvia miltiorrhiza with analysis by HPLC. Journal of Chromatography, 922: 371-375.

Patel, S. 2014. Hibiscus sabdariffa An ideal yet underexploited candidate for neutraceutrical applications. Biomedicine \& Preventive Nutrition. (4): 23-27

Purbowati, I. S. M., Sujiman, dan Maksum, A. 2018. Aktivitas antibakteri senyawa fenolik ekstrak rosela (Hisbiscus sabdariffa) yang dihasilkan dari beberapa variasi metode dan lama pengeringan. Jurnal Teknologi Industri Pertanian.
28(2): 19-27.

Purbowati, I. S. M., Syamsu, K., Warsiki, E., dan Rukmini, H. S. 2016. Optimization of phenols extraction from roselle (Hibiscus sabdariffa) by microwave assisted extraction as antibacterial and antioxidant agents. Jurnal Teknologi Industri Pertanian. 26(1):23-30.

Rostinawati. T., 2009. Aktivitas Antibakteri Ekstrak Etanol Bunga Rosella (Hibiscus Sabdariffa L.) Terhadap Escherichia coli, Salmonella typhi dan Staphylococcus aureus dengan Metode Difusi Agar". Fakultas Farmasi, Univ. Pajajaran, Jatinangor.

Selim, K. A., Khalil, K. E., Abdel-bary, M. S., and Abdel-Azezim, N. A. 2005. Extraction, encapsulation and utilization of red pigments from Roselle (Hibiscus sabdariffa) as natural food colorant. Food science and Technology Dept, Fayoum Univetsity. 1-20.

Shirazian, S. and Ashrafizadeh, S. N. 2010. Mass Transfer Simulation of Caffeine Extraction by Subcritical $\mathrm{CO}_{2}$ in a Hollow-Fiber Membrane Contactor. Journal Solvent Extraction and Ion Exchange. 28(2): 267-286.

Wahid, D.W. 2008. Bunga-Bunga Sekitar Kaya Obat Untuk Kesehatan. Buku Biru. Jogjakarta.

Wang, YL., Xi, G. S., Zhen, Y. C. and Miao, F. S. 2010. Microwave assisted extraction from chinese herb radix puerariae. Journal of Medicinal Plant Research. 4:304-308

Watson, M. 2005. Supercritical Fluid Extraction of Ylang Ylang, PhD in Chemical Engineering. (Unpublished). Department of Chemical Engineering, The University of the West Indies, Trinidad and Tobago.

Widyanto, P. S. dan Nelistya, A. 2008. Rosela Aneka Olahan, Khasiat dan Ramuan. Penebar Swadaya.

$\mathrm{Xu}$, Z. and Howard, L. R. 2012. Analysis of Antioxidant-Rich Phytochemicals. UK: John Wiley and Sons, Ltd., p.72, 208. 